\title{
Formas de colaboración humana entre profesores y alumnos durante la elaboración de simuladores con GeoGebra
}

\author{
Forms of human collaboration between teachers and students during the \\ development of simulators with GeoGebra
}

\author{
Juan Luis Prieto G. \\ ORCID iD 0000-0003-0798-5191 \\ Luis Andrés Castillo B.** \\ ORCID iD 0000-0002-5174-9148 \\ Maximina Márquez T. ${ }^{* * *}$ \\ ORCID iD 0000-0002-0019-8809
}

\begin{abstract}
Resumen
La investigación se centra en las formas de colaboración humana puestas de manfiesto por profesores y alumnos de educación media que participan en una experiencia de elaboración de simuladores con GeoGebra (ESG) en la que intervienen procesos de modelación matemática. Para analizar la colaboración en esta actividad nos apoyamos en la idea de subjetividad proveniente de la Teoría de la Objetivación (RADFORD, 2014). A través de un análisis interpretativo del momento en que un alumno comunica a otros la técnica empleada por él para construir un semicírculo con GeoGebra, fue posible identificar la presencia de la responsabilidad, el compromiso y el cuidado del otro, como las tres formas de colaboración características de la ESG. Además, el análisis permitió identificar el modo en que uno de los profesores promueve algunas de estas formas de colaboración en los alumnos. Las conclusiones sugieren que la manera de gestionar la comunicación de la técnica, la cultura individualista en la escuela y la resistencia al cambio por parte de los alumnos, fueron los tres aspectos que incidieron en la manifestación y promoción de estas formas de colaboración.
\end{abstract}

Palabras clave: Colaboración humana. Simuladores con software dinámico. Subjetividad. Análisis interpretativo.

\begin{abstract}
* Máster en Nuevas Tecnologías Aplicadas a la Educación por la Universidad Autónoma de Barcelona, Universidad de Alicante y Universidad Carlos III de Madrid. Coordinador General de la Asociación Aprender en Red. Profesor Agregado del Departamento de Matemática y Física, Facultad de Humanidades y Educación, Universidad del Zulia (LUZ), Venezuela. Dirección postal: Avenida 16, Ciudad Universitaria "Dr. Antonio Borjas Romero", Núcleo Humanístico, 15165, Maracaibo, Venezuela, código postal 526. E-mail: juanl.prietog@gmail.com.

** Magíster em Educación em Ciencias y Matemática por la Universidad Federal de Pará (UFPA). Coordinador de Tecnologías Digitales y Soporte de la Asociación Aprender en Red, Venezuela. Dirección postal: Guaicaipuro, Calle 65B, No 95-29, Maracaibo, Venezuela, código postal 4001. E-mail: luiscastleb@ gmail.com.

*** Doctora en Investigación Educativa, Universidad de Alicante (UA), Alicante, España. Académica del Departamento de Ciencias Exactas de la Universidad de Los Lagos (ULAGOS), Chile. Dirección postal: Avenida Alcalde Fuchslocher 1305, Osorno, Región de Los Lagos, Chile, código postal 5290000. E-mail: maximina.marquez@ulagos.cl.
\end{abstract}


The research focuses on the forms of human collaboration demonstrated by teachers and secondary school students who participate in an experience of simulator development with GeoGebra (SDG) in which mathematical modeling processes are involved. To analyze the collaboration in this activity, we relied on the idea of subjectivity coming from the Theory of Objectivation (RADFORD, 2014). Through an interpretative analysis of the moment in which a student communicates to others the technique used by them to build a semicircle with GeoGebra, it was possible to identify the presence of responsibility, commitment, and care for the other, as the three forms of collaboration produced in the SDG. In addition, the analysis identified how one of the teachers promoted some of these forms of collaboration in the students. The findings suggest that the way of managing technique communication, individualistic culture in school, and the students' resistance to change were the three aspects that influenced the manifestation and promotion of these forms of collaboration.

Keywords: Human collaboration. Dynamical software simulators. Subjectivy. Interpretative analysis.

\section{Introducción}

La elaboración de simuladores con GeoGebra (ESG) es una actividad educativa no convencional que consiste en la producción de modelos computacionales ${ }^{1}$ y la socialización de las experiencias de producción, en el marco del desarrollo del proyecto comunitario Club GeoGebra para la Diversidad (PRIETO, 2017). Desde sus inicios, en 2013, la implementación de este proyecto con alumnos de educación media (12-16 años) se ha realizado en compañía de una intensa actividad investigativa, focalizada en distintos aspectos de la ESG: (i) las ideas matemáticas movilizadas durante la actividad (RUBIO; PRIETO; ORTIZ, 2016), (ii) las prácticas matemáticas y de modelación que subyacen en la elaboración (GUTIÉRREZ; PRIETO; ORTIZ, 2017; SÁNCHEZ; PRIETO, 2017), y (iii) el aprendizaje producido al elaborar los modelos computacionales, desde un enfoque cognitivo (DÍAZ-URDANETA; PRIETO, 2016; SÁNCHEZ; PRIETO, 2016).

Recientemente, nuestro acercamiento a algunas teorías educativas socioculturales contemporáneas nos ha llevado a reconocer que "la interacción entre los individuos (profesores y alumnos) hace parte de la actividad" (RADFORD, 2017, p. 140), por lo tanto, consideramos importante centrar la atención en esos aspectos sociales de la ESG que han pasado desapercibidos en los trabajos antes mencionados.

Por ejemplo, un foco de investigación que cobra relevancia para nosotros se refiere a las formas de colaboración entre alumnos y profesores cuando trabajan, conjuntamente, para producir los modelos computacionales. En vista de ello, este trabajo presenta evidencias de las formas de colaboración que se producen en una experiencia de ESG y de cómo estos modos de colaborar son promovidos por quienes participan en la actividad. Nuestra intención es proporcionar información que permita fomentar en los Clubes GeoGebra una nueva ética

\footnotetext{
${ }^{1}$ Según Parnafes (2007, p. 416), los modelos computacionales son "un tipo específico de representación externa: una representación gráfica dinámica e interactiva basada en computadora".
} 
comunitaria fundamentada en cualidades como la responsabilidad, el compromiso y el cuidado del otro (RADFORD, 2017).

\section{Problemática}

La influencia de la perspectiva cognitiva en la investigación dentro del campo de la educación matemática ha conducido a una comprensión generalizada del aprendizaje como proceso guiado por mecanismos intelectuales de pensamiento y/o razonamiento que median el encuentro del sujeto con el conocimiento matemático (MORENO-ARMELLA; WALDEGG, 1992; RADFORD, 2006). En un sentido ontológico, esta manera de comprender el aprendizaje se fundamenta en una concepción del alumno como sujeto autónomo (RADFORD, 2017, p. 151), capaz de aprender "por sí mismo", sin mayor influencia del entorno cultural y social. Esta perspectiva coloca al alumno en "[...] el centro del significado, de la conceptualización y de la intencionalidad. Todo emana de él. [...] el individuo termina alienado, es decir, alejado del mundo concreto e histórico".

Aunque puede atribuirse a la perspectiva cognitiva el haber ofrecido las primeras herramientas conceptuales necesarias para enfrentar las contradicciones engendradas por una enseñanza de las matemáticas comprometida con la difusión del saber, la atención en el alumno como sujeto autónomo trajo consigo otros problemas derivados de un compromiso de la educación matemática con el desarrollo individual de estructuras mentales cada vez más sofisticadas (RADFORD, 2013).

Como consecuencia de esto, el alumno termina alienado, es decir, "encerrado en sus propias cavilaciones, [...] alejado del mundo concreto e histórico" (RADFORD, 2013, p. 151). Esta realidad dio origen al surgimiento de las teorías educativas socioculturales contemporáneas, hacia finales de los años ochenta, las cuales se han dedicado a repensar la relación individuo-sociedad, produciendo estudios que conceptualizan el aprendizaje de las matemáticas como un fenómeno social, cultural e histórico (BARTOLINI-BUSSI, 1991; LERMAN, 1992; BOERO et al., 1995).

Desde la perspectiva sociocultural, los modos histórico-culturales de interacción y colaboración entre alumnos y profesores que surgen en la actividad matemática escolar cobran relevancia en la investigación, sobre todo al ser conceptualizados como instancias sociales de posicionamiento crítico ante el saber. Sin embargo, Radford (2013) nos alerta sobre lo mucho que queda por hacer para que la interacción social deje de ser un instrumento utilitario de domesticación de la conciencia y de alienación en la clase de matemáticas. Aunque la alienación 
no es la finalidad de la ESG, vemos necesario realizar estudios que nos permitan entender las formas de colaboración humana producidas en el seno de esta actividad, especialmente aquellas no alienantes que promuevan la constitución de sujetos reflexivos y éticos.

En este sentido, nos preguntamos: ¿qué formas de colaboración se producen entre quienes participan en experiencias de ESG? ¿En qué medida estas formas de colaboración se contraponen a la cultura de trabajo individualista dominante en escuelas a las que pertenecen estos sujetos? ¿De qué manera el profesor promueve estas formas de colaboración en el desarrollo de las experiencias de elaboración?

\section{Marco teórico}

Nuestra investigación se fundamenta en la Teoría de la Objetivación (TO), una perspectiva histórico-cultural de la enseñanza y aprendizaje de las matemáticas de inspiración Vigotskiana (RADFORD, 2008), que coloca en el centro de sus planteamientos la idea de actividad o labor conjunta. Para la TO, la labor conjunta se entiende como "un evento creado por una búsqueda común - es decir una búsqueda con otros - de la solución a un problema planteado, búsqueda que es al mismo tiempo cognitiva, emocional y ética" (RADFORD, 2017, p. 125). En este sentido, asumimos que la ESG es una forma de labor conjunta caracterizada por la producción de modelos computacionales que representan las cualidades de forma y dimensión presentes en fenómenos de la realidad.

La interpretación de la ESG como labor conjunta nos lleva a considerar dos ideas importantes para nuestro estudio. Por un lado, toda actividad es guiada por un objeto, es decir, por aquello que le confiere su orientación. Según Leontyev (1977), toda actividad humana responde a determinada necesidad (sea ésta material o ideal) de los individuos implicados en ella, la cual se objetiva materialmente en el motivo que impulsa la actividad.

En este sentido, el objeto es aquello a lo que tienden las acciones de los individuos. Por ejemplo, el objeto de la ESG podría ser tanto la producción de modelos computacionales, correspondientes a ciertas realidades naturales o artificales (PRIETO; GUTIÉRREZ, 2015, 2016, 2017), como la comprensión del modo en que estos modelos son producidos por los alumnos.

En cualquier caso, la labor conjunta desplegada en torno a la ESG puede favorecer el encuentro con formas culturalmente codificadas de pensar y actuar sobre los objetos 
geométricos $^{2}$ que conforman a los modelos computacionales, en razón de su construcción por medio del GeoGebra. En la TO, el encuentro de los individuos con los saberes (matemáticos, científicos, estéticos, legales etc.) hacen parte de procesos sociales, corporales, materiales y simbólicos de objetivación, esto es, de procesos de toma de conciencia crítica y progresiva de formas de expresión, acción y pensamiento, constituidas histórica y culturalmente. (RADFORD, 2018).

Por otro lado, si la labor conjunta implica la búsqueda con otros, entonces ésta no sólo tiene que ver con saberes, sino también con subjetividades (RADFORD, 2017). En la TO, la idea de subjetividad se relaciona con la transformación del alumno en tanto sujeto humano en relación con el otro; un sujeto capaz de posicionarse críticamente ante el saber culturalmente constituido y ante sus formas de producción (RADFORD, 2014).

Dependiendo de la actividad de aprendizaje y enseñanza en la que se participe, la transformación personal de los alumnos puede ser alienante o no, razón por la cual conviene que se ponga atención tanto en los medios materiales e intelectuales que emplean alumnos y profesores en el devenir de la actividad del aula, aquella que hace parte consustancial de los procesos de objetivación como en los modos en que ellos interaccionan y cooperan para lograr el objeto de la actividad.

\subsection{Modos de producción de los modelos computacionales en la ESG}

Para Marx (citado por Radford, 2014), la labor puede entenderse en razón de dos grandes categorías. La primera se refiere a los medios de producción, esto es, la manera de producir de los individuos. Según Radford (2014, p. 144), los medios de producción tienen que ver con las prácticas culturales de producción y reproducción de la vida material y espiritual, en las que entran en juego diversos recursos semióticos en forma de artefactos materiales e intelectuales (p. ej., lenguaje, gestos, diagramas, software de aplicación, entre otros). Para la TO, tales recursos representan los medios semióticos de objetivación "que se utilizan para hacer visible una intención y para llevar a término una acción” (RADFORD, 2005, p. 203).

Durante la ESG, alumnos y profesores se involucran en procesos de modelación que demandan la combinación de distintos medios semióticos para idear formas más o menos sofisticadas de resolver las tareas de simulación que la propia actividad les demanda. En la Figura 1 indicamos, con sendas flechas, los cuatro procesos de modelación característicos de la

\footnotetext{
${ }^{2}$ Los objetos geométricos incluyen las figuras 2D y 3D, sus relaciones, propiedades y posibles transformaciones geométricas.
} 
ESG: problematización, matematización, trabajo matemático e interpretación. Una explicación más detallada de estos procesos se ofrece en Prieto (2017).

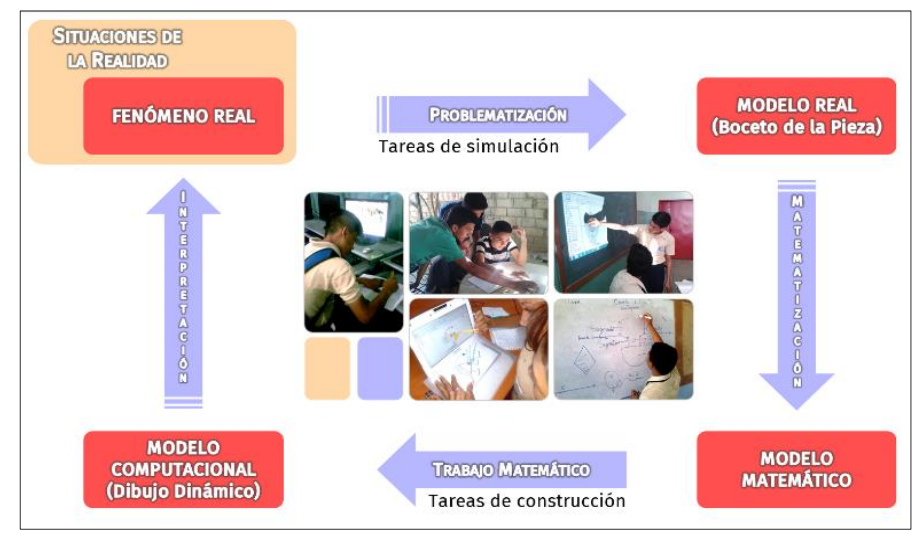

Figura 1 - Ciclo de modelación en la elaboración de simuladores Fuente: Prieto y Ortiz (2019)

Cada tarea de simulación se refiere al trabajo de representar con GeoGebra alguna de las partes que conforman al fenómeno seleccionado para tal fin. Hasta este momento, los objetos geométricos no intervienen en actividad. La resolución de este tipo de tareas comienza con la producción de un boceto (dibujo a mano alzada) de la parte en cuestión. Este boceto se convierte en el modelo real para la tarea de simulación. Un cambio en la interpretación del boceto, que pasa a verse desde una perspectiva geométrica, conduce a los alumnos a vincular las formas, dimensiones y movimientos propios del modelo real con ciertos objetos de la geometría. Llamamos modelo matemático al conjunto de objetos geométricos que son evocados como objetos ideales para la representación del modelo real.

A partir de ese momento, alumnos y profesores se encuentran en condiciones de formular y resolver una serie de tareas de construcción geométrica con el GeoGebra; una por cada objeto del modelo matemático. En el contexto de la ESG, la resolución prototípica de una tarea de construcción con GeoGebra comprende las siguientes etapas: (i) seleccionar la herramienta del software que permite construir el objeto geométrico de la tarea; (ii) identificar en la vista gráfica la presencia o ausencia de cada elemento requerido por la herramienta; (iii) construir los elementos faltantes con base en relaciones entre lo espacial y lo teórico evocado por el dibujo; (iv) aplicar la herramienta (PRIETO; ORTIZ, 2019).

En el desarrollo de esta labor conjunta se producen y reproducen técnicas de construcción $^{3}$ que son mediadas, principalmente, por las herramientas del software (SÁNCHEZ; PRIETO, 2017). La producción de una técnica se basa en el establecimiento de relaciones entre las propiedades espaciales del dibujo geométrico en papel (modelo

\footnotetext{
${ }^{3}$ Procedimentos seguidos para construir un dibujo dinámico. Éstos se componen de pasos y acciones.
} 
matemático) y las propiedades geométricas del objeto que este dibujo intenta modelar (LABORDE, 1997). El producto obtenido al emplear una técnica de construcción es un dibujo dinámico, esto es, un dibujo creado en un ambiente de geometría dinámica, de manera que “conserve ciertas propiedades espaciales impuestas cuando se desplace por uno de los puntos básicos del dibujo" (LABORDE, 1997, p. 42).

Durante el trabajo matemático se producen distintos tipos de dibujos dinámicos. Un primer tipo de dibujo se obtiene al resolver cada tarea de construcción, indistintamente del lugar que ésta ocupe en la secuencia de trabajo (Figura 2 a). El segundo tipo está asociado al conjunto de dibujos dinámicos que responden a las tareas de construcción del mismo modelo matemático (Figura 2 b). Al ser la respuesta a una tarea de simulación, este dibujo recibe el nombre de modelo computacional. El tercer tipo de dibujo es aquel formado por el conjunto de modelos computacionales que dan forma y sentido al simulador.

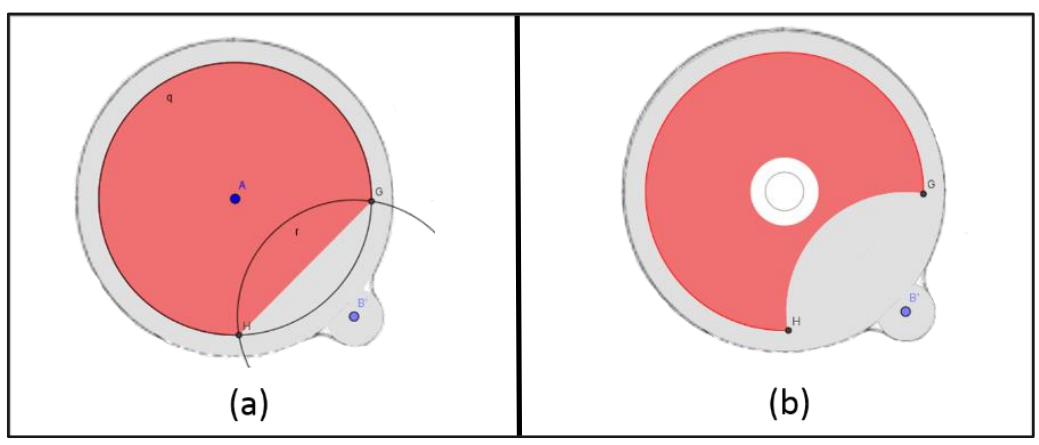

Figura 2 - Ejemplo de dos tipos de dibujos dinámicos obtenidos durante el trabajo Fuente: elaborado por los autores

En cualquiera de los casos, conviene someter el dibujo dinámico obtenido a la prueba de arrastre, esto con la intención de validar las construcciones realizadas o detectar inconsistencias en las técnicas empleadas. Esta prueba es una modalidad de arrastre de los entornos dinámicos que consiste en:

[...] mover un punto libre o semi-libre [dependiente] para ver si el dibujo mantiene las propiedades iniciales. Si esto es así, entonces la figura pasa la prueba; sino, el dibujo no fue construido de acuerdo a las propiedades geométricas que se quería que tuviese (ARZARELLO et al., 2002, p. 67).

Una vez que los alumnos resuelven todas las tareas de construcción derivadas de un mismo modelo matemático, el trabajo matemático se da por concluido. Este proceso se vuelve a retomar para el resto de tareas de construcción que surjan al resolver las demás tareas de simulación.

\subsection{Relaciones de producción de los modelos computacionales en la ESG}


La segunda categoría de la labor, según Marx (citado por Radford, 2014) está referida a las relaciones de producción. Para Radford (2014), las relaciones de producción tienen que ver con las formas de colaboración humana que mediatizan las interacciones entre los individuos inmersos en la actividad. En escenarios escolares en donde domina la lógica capitalista, las relaciones de producción quedan supeditadas por formas de trabajo individualistas que reducen al alumno a lo que este es capaz de producir para sí mismo y para otros. Como consecuencia, el único futuro posible para los alumnos, en estos escenarios, no es otro que el de la alienación engendrada en el aula (RADFORD, 2017).

Ante tales circunstancias, Radford (2013) refiere que no basta con mostrar las contradicciones del sistema capitalista en el campo educativo. Es necesario que alumnos y profesores establezcan relaciones sociales que favorezcan el surgimiento de una ética de cooperación humana diferente a la de la lógica del capital; una ética que propicie "la creación de nuevos individuos capaces de reflexionar críticamente de manera matemática sobre las cuestiones urgentes de sus comunidades y su mundo" (RADFORD, 2017, p. 141).

Lo anterior supone la emergencia de un Ser cuyas interacciones sociales giran en torno a una ética comunitaria que favorece el despertar de una sensibilidad especial hacia el Otro, la solidaridad colectiva y el desarrollo de una conciencia crítica. En esta perspectiva, la relación con el Otro se convierte en el fundamento de la existencia del Ser en tanto crea condiciones para el reconocimiento de otras voces y perspectivas, y su propia constitución como un sujeto cultural e histórico único.

La ética comunitaria en clases de matemática refleja formas de colaboración como la responsabilidad, el compromiso hacia los demás y el cuidado del otro (RADFORD, 2017), aspectos de una subjetividad emergente que trasciende el rigor matemático de la clase, hacia una dimensión más humana de transformación del alumno (LEÓN; LASPRILLA, 2018). Para Radford (2017) la subjetividad es un proceso social de coproducción de la condición humana dentro de un contexto cultural e histórico, en donde los profesores y los alumnos se encuentran en relación de presencia mútua.

El Cuadro 1 describe las tres formas de colaboración característica de una ética comunitaria asociada a los procesos de subjetivación en clases de matemáticas.

\begin{tabular}{|c|c|}
\hline Forma de colaboración & Conceptualización \\
\hline Responsabilidad & $\begin{array}{l}\text { Acto ético de vinculación, conexión y enlace con el prójimo que } \\
\text { se expresa en la respuesta que damos al llamado del otro. El rasgo } \\
\text { fundamental de este acto es su carácter dialógico, lo que permite } \\
\text { entender la responsabilidad como una manera de responder y de } \\
\text { comprometernos con el otro. }\end{array}$ \\
\hline
\end{tabular}




\begin{tabular}{|c|l|}
\hline Compromiso & $\begin{array}{l}\text { Capacidad de adquirir cierta responsabilidad sobre las } \\
\text { necesidades de la obra común. Cuando una persona adquiere un } \\
\text { compromiso dirigido hacia los demás, se muestra solidario a la } \\
\text { causa de la persona y del colectivo. }\end{array}$ \\
\hline Cuidado del otro & $\begin{array}{l}\text { Capacidad de verse a sí mismo en el otro, que implica el } \\
\text { reconocimiento de su necesidad y la acción solidaria } \\
\text { intersubjetiva correspondiente. A partir de esto, los individuos se } \\
\text { sienten reconocidos, valorados y aceptados los unos por los otros. }\end{array}$ \\
\hline
\end{tabular}

Cuadro 1 - Formas de colaboración humana durante una clase de matemáticas Fuente: elaborado por los autores, con base en Radford (2017)

Si bien la aparición de la nueva ética comunitaria no es algo que se dé "por arte de magia” (RADFORD, 2017, p. 158), es posible que durante la ESG estas formas de colaboración aparezcan, sin que necesariamente sean reconocidas por profesores y alumnos. Por lo tanto, con el fin de fomentar su aparición en la dinámica de trabajo de los clubes GeoGebra, nos preguntamos: ¿cómo son las formas de colaboración humana producidas en el trabajo matemático que permiten el posicionamiento de alumnos y profesores como sujetos de la educación en ese proceso? ¿Cuáles son las acciones específicas que despliegan los profesores en procura de fomentar estas formas de colaboración humana entre sus alumnos?

Para proporcionar respuestas a estas preguntas, vemos necesario describir el modo en que profesores y alumnos del club GeoGebra colaboran, conjuntamente, en la producción y comunicación de las técnicas de construcción que dan cuerpo a los modelos computacionales. En este sentido, nos hemos propuesto: (i) caracterizar las formas de colaboración humana entre quienes participan durante el trabajo matemático y, particularmente, cuando los alumnos intentan comunicar sus técnicas de construcción al profesor, y (ii) describir las acciones del profesor que favorecen el surgimiento de tales formas de colaboración durante la labor conjunta.

\section{Metodología}

El presente trabajo se ubica dentro del paradigma de investigación cualitativa en educación matemática, especialmente entre aquellos estudios de naturaleza descriptiva e interpretativa. Según Bogdan y Biklen (1994), algunas características de las investigaciones cualitativas son: (i) los datos son captados directamente del ambiente natural, (ii) los investigadores están preocupados más por los procesos que por los productos, y (iii) los resultados tienen una fuerte componente descriptiva.

Para dar cuenta de las formas de colaboración humana que surgen a lo largo del trabajo matemático, asumimos como aproximación metodológica el estudio cualitativo de un caso proveniente del ámbito de comunicación de una técnica de construcción con GeoGebra 
(PRIETO; ORTIZ, 2019), en donde tiene lugar la labor conjunta (unidad de análisis). Nos referimos al caso de Santiago ${ }^{4}$, un alumno que participó en el proyecto Club GeoGebra.

\subsection{El caso de Santiago}

Santiago era un joven que, para el momento de la investigación, cursaba el tercer año de educación media en una institución oficial localizada en la ciudad de San Rafael de El Moján, en Venezuela. Tras la incorporación al Club GeoGebra de la institución, este alumno decidió trabajar en la producción del modelo computacional de un brazo robótico ${ }^{5}$ (Figura 3 a) en la vista gráfica del GeoGebra, bajo la orientación de un profesor de matemáticas y física, quien cumplía el rol de promotor responsable del club.

El simulador de Santiago fue elaborado por partes y de forma progresiva a través de sesiones de trabajo semanales, cada una de dos horas de duración. La primera tarea de simulación atendida por el alumno fue la siguiente: representar el antebrazo en el GeoGebra. Sobre el boceto del antebrazo, Santiago identificó cinco figuras geométricas: dos semicírculos, dos círculos y un rectángulo (Figura $3 \mathrm{~b}$ ).

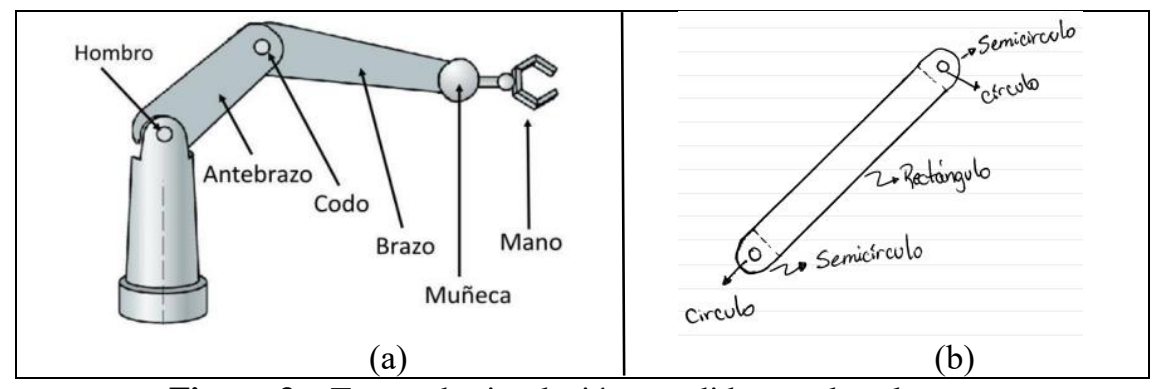

Figura 3 - Tareas de simulación atendidas por los alumnos Fuente: Peley (2016)

Algunas sesiones de trabajo con Santiago fueron dedicadas a reflexionar sobre la manera de producir los dibujos dinámicos correspondientes a cada objeto geométrico de la Figura $3 \mathrm{~b}$. En estas reuniones, además de Santiago y el promotor, participaban otros alumnos del mismo club interesados en cooperar con el trabajo realizado por el joven.

\subsection{Contexto de la investigación y participantes}

Una de las sesiones de trabajo del club de Santiago fue dedicada a revisar las construcciones de los alumnos que, hasta ese momento, se habían realizado. Tal revisión estuvo

\footnotetext{
${ }^{4}$ Usamos el nombre Santiago como seudónimo para proteger la identidad del alumno.

5 Imagen de referencia: <https://goo.gl/WBuuDm>.
} 
a cargo de dos promotores del proyecto Club GeoGebra (Juan y Rafael), distintos de aquel que se desempeñaba como responsable del espacio (Luis). Durante esta reunión, los alumnos debían comunicar las técnicas de construcción que emplearon para producir sus modelos computacionales. En el caso de Santiago, el joven explicó a los promotores las técnicas de construcción con GeoGebra de cada uno de los objetos geométricos de la Figura 3 b. Durante su explicación, Santiago encontró apoyo en algunos de sus compañeros del club y en su promotor (Luis), quienes se sumaron a la discusión para acompañarle y darle ánimos.

El momento de más apoyo hacia Santiago ocurrió cuando el joven trataba de comunicar la técnica correspondiente a la cuarta tarea de construcción: construir un semicírculo homólogo a otro previamente dibujado. En ese momento, participaron en la discusión los alumnos Elías, Yolanda y Leonardo ${ }^{6}$, y los promotores Juan, Rafael y Luis. Los alumnos deciden cooperar con Santiago al percatarse que el joven tiene dificultades para explicar adecuadamente la técnica, y alentados por Juan y Rafael, quienes les invitaban, reiteradamente, a participar con ellos en la discusión.

\subsection{Los datos de la investigación}

Los datos de la investigación provienen del modo en que interaccionan alumnos y promotores cuando Santiago intenta comunicar al grupo la técnica de construcción del semicírculo. Para recolectar los datos, se hizo un registro de toda la sesión en formato de vídeo, con el propósito de capturar la realidad compleja del trabajo conjunto realizado por estos individuos, mientras transitan por el proceso trabajo matemático que fue descrito en apartados anteriores. De esta manera, los datos fueron tomados de dos de los cuatro registros de vídeo que componen las grabaciones de la sesión.

\subsection{Análisis de los datos}

El análisis de los datos se realizó por etapas. La primera etapa consistió en preparar la información de los vídeos mediante el siguiente procedimiento: (i) exploramos cada registro a fin de entrar en contacto con los datos; (ii) identificamos los intervalos de tiempo en los que se explica la técnica de construcción del semicírculo; y (iii) transcribimos las interacciones producidas en esos intervalos de tiempo, considerando solo el discurso oral producido por los

\footnotetext{
${ }^{6}$ Los nombres Elías, Yolanda y Leonardo son usados como seudónimos para proteger la identidad de los alumnos. 
participantes. Para la trascripción de los episodios, utilizamos un instrumento similar al mostrado en el Cuadro 2.

\begin{tabular}{|l|l|l|}
\hline No. Línea & Contenido de la trascripción & Comentarios interpretativos \\
\hline & & \\
\hline
\end{tabular}

Cuadro 2 - Instrumento usado para la trascripción de los episodios

Fuente: elaborado por los autores

En la segunda etapa identificamos los episodios destacados, es decir, aquellos pasajes de la transcripción en los que se muestran posibles evidencias de las formas de colaboración humana puestas en movimiento durante la comunicación de la técnica por parte de Santiago (MUÑOZ-CATALÁN; CARRILLO; CLIMENT, 2010; POWELL; FRANCISCO; MAHER, 2003; RADFORD, 2015).

En la tercera etapa examinamos los segmentos destacados por medio de un análisis interpretativo (RADFORD, 2015) bajo el siguiente procedimiento: (i) definimos las categorías analíticas de colaboración que podían servirnos como referentes teóricos para el análisis, atendiendo a ciertos indicios de la presencia de tal o cual modo de cooperación entre los participantes (Cuadro 3); e (ii) interpretamos lo ocurrido en cada segmento a la luz de las categorías analíticas. Mientras interpretamos, tratamos de contextualizar los segmentos (o parte de éstos) añadiendo tanto imágenes de la discusión que reflejaran cuestiones de la colaboración que no fueran posibles de ver a través del discurso oral, como nuestros comentarios interpretativos.

\begin{tabular}{|c|c|c|}
\hline Forma de colaborar & Categoría & Indicio(s) \\
\hline \multirow{3}{*}{ Responsabilidad } & Sentido de vigilancia & $\begin{array}{l}\text { Reconoce signos de frustración, ansiedad o } \\
\text { incomprensión en el otro y se involucra para } \\
\text { ofrecer alguna ayuda. }\end{array}$ \\
\hline & $\begin{array}{l}\text { Disposición a responder o } \\
\text { rendir cuenta de algo }\end{array}$ & $\begin{array}{l}\text { Se dispone a cooperar con el otro, aceptando el } \\
\text { llamado a trabajar conjuntamente. }\end{array}$ \\
\hline & Pluralidad de perspectivas & $\begin{array}{l}\text { - Escucha lo que el otro tiene que decir e intenta } \\
\text { ver la situación desde esa perspectiva, aunque no } \\
\text { se esté de acuerdo. } \\
\text { - Fija posición respecto a los diferentes puntos de } \\
\text { vista, sin pretensiones de imponerse. }\end{array}$ \\
\hline \multirow{2}{*}{ Compromiso } & Motivación & $\begin{array}{l}\text { Reconoce el esfuerzo del otro y lo valora, incluso } \\
\text { si éste no conduce al resultado esperado. }\end{array}$ \\
\hline & Dedicación & $\begin{array}{l}\text { Ofrece intensamente su ayuda (ideas, sugerencias } \\
\text { y otros mecanismos de mejora) en pro de asegurar } \\
\text { el progreso hacia el resultado esperado. }\end{array}$ \\
\hline Cuidado del otro & Empatía & $\begin{array}{l}\text { Se muestra sensible ante los signos de frustración, } \\
\text { ansiedad o incomprensión del otro, y reacciona en } \\
\text { consecuencia. }\end{array}$ \\
\hline
\end{tabular}




\begin{tabular}{|l|l|l|}
\hline & Actitud solidaria & $\begin{array}{l}\text { Se muestra animado a ofrecer su ayuda al otro } \\
\text { cuando éste lo necesita. }\end{array}$ \\
\hline
\end{tabular}

Cuadro 3 - Categorías de análisis de las formas de colaboración en los clubes GeoGebra Fuente: elaborado por los autores

Finalmente, en la cuarta etapa decidimos cómo organizar los resultados para su presentación en el próximo apartado.

\section{Resultados}

Los resultados de la investigación están organizados en dos apartados. El primer apartado describe las formas de colaboración que ocurrieron durante la sesión analizada. El segundo apartado está referido al modo en que los promotores promueven estas formas de colaboración en los alumnos.

\subsection{Sobre las formas de colaboración}

La responsabilidad es la forma de colaboración que más se manifestó a lo largo del análisis. Esta categoría se vio especialmente reflejada en la relación dialógica que mantienen Juan (el promotor) y Santiago en la búsqueda de una forma conveniente de comunicar la técnica de construcción. La vinculación con el prójimo que caracteriza esta forma de colaboración fue materializada tanto en las acciones de Juan hacia los alumnos, como de los alumnos hacia el promotor y entre ellos mismos.

Para esta forma de colaboración, se encontraron evidencias de la disposición a responder o rendir cuenta de algo por parte de Santiago, quien, pese a las recurrentes fallas que comete al comunicar la técnica, se mantuvo dispuesto a cooperar con Juan y los demás compañeros, aceptando el llamado que estos le hicieran a trabajar conjuntamente. En el siguiente segmento se puede notar esta forma de responsabilidad en cada una de las repuestas de Santiago a las inquietudes de Juan, quien trata que el joven dote de sentido a los pasos de la técnica.

Juan: ¿Cómo lo hiciste? Ven a la pizarra y me explicas.

Santiago: Con la simetría axial [herramienta del GeoGebra usada en la construcción]. Juan: Pero, ¿cómo usaste la Simetría axial? A ver.

Santiago: Nosotros comenzamos con esta recta [recta a", señalada con un movimiento de la mano sobre la línea (Imagen 1): 


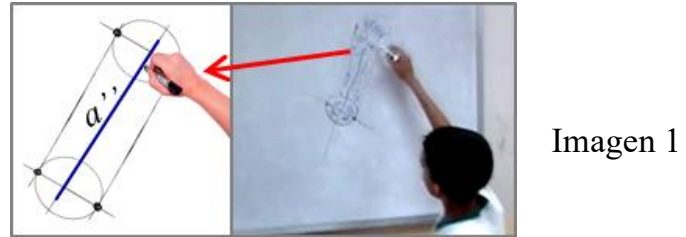

Juan: Esa recta ya la teníamos, porque esa es al que se rota con el ángulo "deslizador" [se refiere al ángulo $\alpha$, definido a través de una reflexión]. Esa ya se conocía. Aja, dale.

Santiago: Seguimos... [se muestra pensativo (Imagen 2a)]... Ésto [señala al semicírculo 1 (Imagen 2b)], como si fuéramos a copiarlo aquí [señala con la mano el lugar que ocupa el semicírculo 2 en el dibujo (Imagen 2c)]. Reflejándolo. Y... [se queda callado].

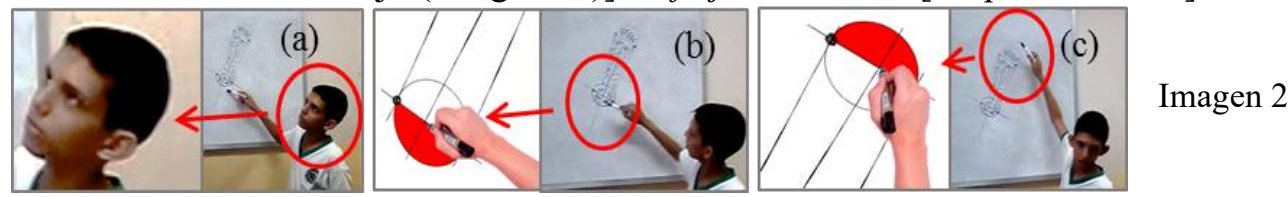

Juan: Aja, pero ¿cómo? Explícame bien lo que hiciste... Esto lo tienes ya [remarca el semicírculo 1 en la pizarra]. Tú lo que quieres es copiar esto [señala al semicírculo 1] allá [señala el lugar que debería ocupar en la pizarra el semicírculo 2 al ser una reflexión del semicírculo 1]. Ahora, ¿cómo lo copiaste?

Santiago: Copiando una simetría axial.

Con respecto al compromiso, el análisis muestra que esta forma de colaboración se vio reflejada en las acciones de Juan (el promotor) hacia los alumnos, y especialmente hacia Santiago, durante toda la sesión. Por un lado, se encontraron evidencias de cómo Juan reconoce el esfuerzo responsable de Santiago por atender sus inquietudes, pese a las dificultades que el joven tiene para Comunicar los pasos de la técnica.

Este reconocimiento es un acto de motivación de Juan hacia Santiago, que busca mantener al alumno comprometido en la causa común que les convoca. Tal forma de compromiso se observa en el siguiente fragmento, el cual muestra al promotor tratando las frustraciones de Santiago como algo que puede ocurrir a cualquier otro alumno enfrentado a la misma situación de comunicar los pasos de su técnica, pero también haciéndole ver que el origen de sus problemas está en sí mismo, es decir, en el miedo que padece y le paraliza.

Juan: ¡Está fuerte [la situación]! ¿Verdad? Porque el problema que tienes tú, Santiago es que los nervios te están matando o que realmente no recuerdas lo que es una mediatriz. Vamos a empezar por allí. ¿Si recuerdas lo que es la mediatriz de un segmento? [dirige la pregunta a Santiago] ¿No sabes?

Santiago: [Gira la cabeza para decir que "no"].

Juan: Vamos a partir de allí. Presten atención. La mediatriz de un segmento, Santiago, es una recta. Eso es lo primero que debes tener en cuenta. Lo voy a anotar aquí [en la pizarra] para que no se te pase [olvide]: "Mediatriz de un segmento: es una recta"... [escribe en la pizarra].

Por otro lado, como puede notarse en el segmento anterior, muy a pesar del estado de frustración en el que se encuentra Santiago, Juan persiste en ofrecer su ayuda al alumno como un acto pleno de dedicación que deja frutos al término de la sesión, cuando el joven se vuelve capaz de identificar sobre la pizarra el segmento correspondiente a la mediatriz que él utiliza como eje de reflexión en su técnica. En este momento, el reconocimiento del trabajo de Santiago 
por parte del promotor viene cargado de una alegría que se siente en el tono de las palabras de Juan, pero también en la expresión facial de Leonardo, quien comparte la misma alegría del promotor al ver a su compañero salir adelante.

Juan: ¿Dónde está [el segmento]? ¿Dónde está?

Santiago: Debe estar... [señala los extremos del segmento, es decir, los centros de las semicirculos

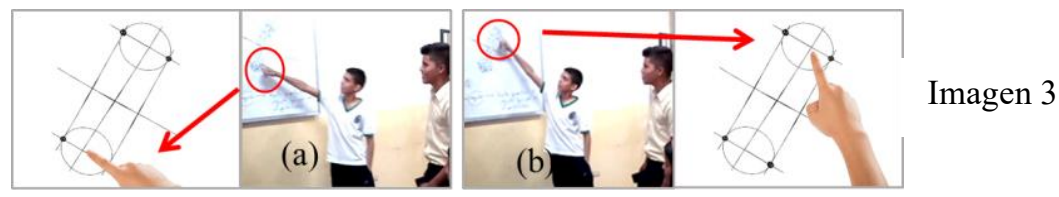

Juan: ;Eso es, campeón! ¡Eso es! Es que no puede ser otro [el segmento], porque esta recta [la mediatriz (Imagen 4a)] pasa por un punto medio, obligado. Este debe ser el punto medio [señala el punto medio del segmento (Imagen 4b)] por lo tanto, éste [punto] es un extremo [señala el centro del semicírculo 2 (Imagen 4c)] y éste es otro extremo [señala el centro del semicírculo 1 (Imagen 4d)] ¿Qué pasa contigo? [refiriéndose a Santiago], que tu no tenías dibujado el segmento [señala el segmento a través de un movimiento de la mano de un extremo al otro (Imagen 4e)], tú lo que tenías eran los extremos [señala cada extremo con su dedo índice].

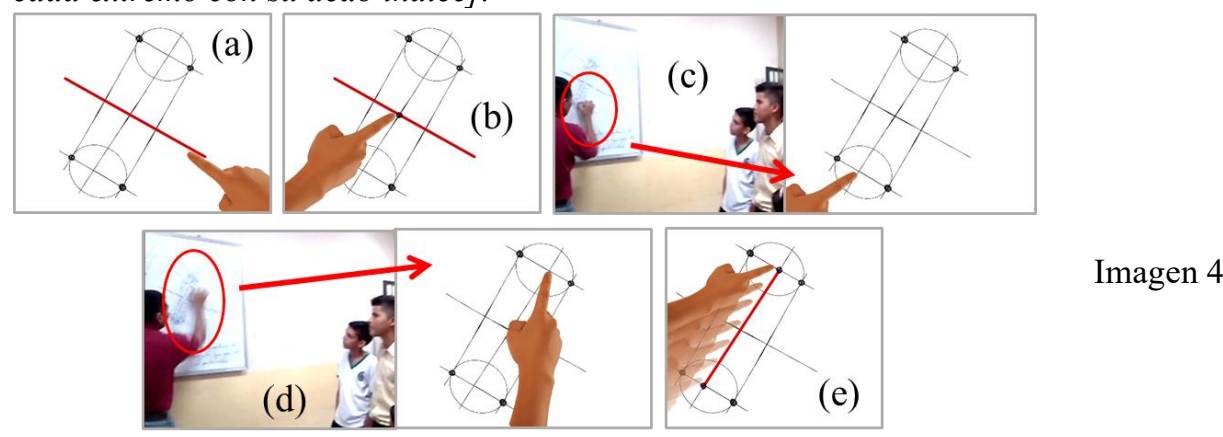

El cuidado del otro se manifestó de una forma muy particular en las acciones de Juan (el promotor) hacia Santiago, al tratar de protegerlo de aquellos quienes buscaban imponer su punto de vista al joven, aunque de forma inconsciente. Por ejemplo, en el siguiente segmento el profesor, quien muestra empatía hacia Santiago, pide insistentemente a Luis (promotor responsable del club al que asiste Santiago) que no diga las respuestas al joven, ya que ese acto no representa una verdadera ayuda para él. Este modo de actuar de Luis es un reflejo de la necesidad de sobreprotección que puede sentir un promotor hacia sus alumnos cuando les ve desenvolverse en situaciones de alta tensión, como ocurre cuando comunican a otros sus técnicas de construcción.

Santiago: Éstos [señala con el marcador los extremos del semicírculo (Imagen 5)].

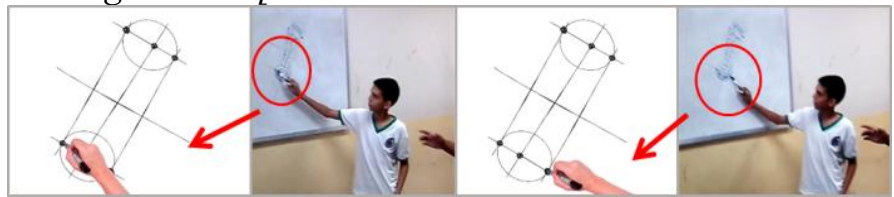

Imagen 5

Juan: ¿Esos [puntos]? ¿esos?

Santiago: [se muestra dudoso (Imagen 6a) y señala hacia los extremos del semicírculo 2 (Imagen 6b)]. 


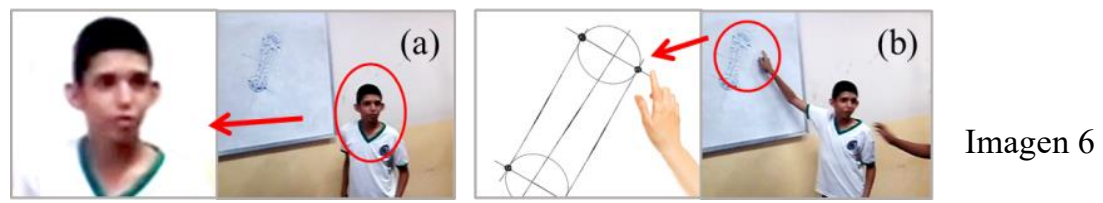

Juan: Ya va. La mediatriz de estos puntos [señala los extremos del semicírculo 1]. Dame el marcador [dirigiéndose a Santiago], para que lo vean más rápido. No le soples [digas] Luis.

Luis: Yo no le estoy soplando [diciendo].

Juan: No le digas. Aja, aquí hay dos puntos [marca dos puntos en la pizarra y los denota como A y B]. Este se llama A y este se llama B.

\subsection{Sobre el modo en que se promueven las formas de colaboración}

El análisis muestra que Juan (el promotor) realizó esfuerzos en la sesión por promover el cuidado del otro y la responsabilidad en los alumnos. En lo que respecta al cuidado del otro, se obtuvieron evidencias del modo en que este promotor fomenta la empatía en Elías, con el fin de hacerlo sensible ante los signos de incomprensión en Santiago y que se disponga a ofrecerle su ayuda. Esta forma de cuidado se manifiesta a partir de un gesto de frustración que hace Santiago al verse incapaz de responder las preguntas de Juan. El hecho sirvió para que el promotor invitara al resto de los alumnos a ver este signo de incomprensión como un llamado de auxilio del prójimo, que debía ser contestado de manera corresponsable.

Santiago: [sube las manos a la cabeza en señal de que ha cometido un error (Imagen 7)].

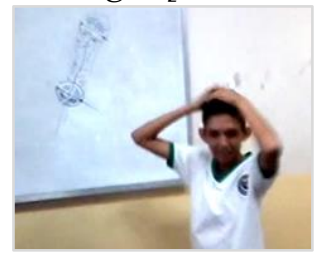

Imagen 7

Juan: Aja, ¿cuál es [el eje de reflexión]? iAyayay! Ayúdenlo allí [se dirige a los alumnos presentes].

Elías decide atender el llamado de Juan, dirigiéndose a la pizarra con el fin de explicar aquello que Santiago no comprende. Al no mostrarse sensible frente al problema de Santiago, el promotor interviene para detener a Elías en su intento de dar la respuesta correcta y pedirle que tratara de comprender la situación de su compañero actuando en correspondencia. Este llamado del promotor es apoyado por Leonardo, quien le recuerda a Elías que él no siempre estará con Santiago para darle respuestas a sus inquietudes. Como consecuencia, Elías toma a Santiago por el hombro, lo lleva a la pizarra y comienza a dialogar con él. Con este gesto, Elías le indica a Santiago que reconoce su necesidad y frustración, y que además está dispuesto a ayudarlo.

Elías: [se dirige a la pizarra a explicar aquello que Sergio no puede explicar].

Juan: Pero no le digas [dirigiéndose a Elías], ya va.

Elías: [se detiene en su intención de dar una respuesta (Imagen 8)]. 


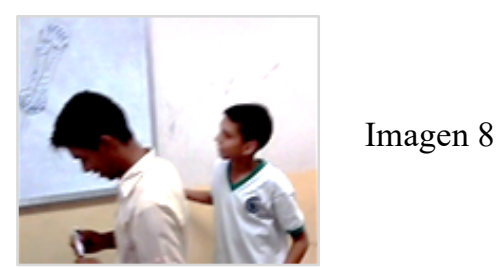

Juan: Elías, vamos a ayudarlo a él [se refiere a Santiago].

Leonardo: Elías, ese día [del Encuentro de Clubes GeoGebra], lamentablemente, no vas a poder dar la respuesta por él [por Santiago].

Elías: Vamos a... [toma a Santiago por el hombro (Imagen 9a), lo acerca a la pizarra y comienza a dialogar con él sobre la construcción].

Elías: ... que ellos crean que... cuando la figura esté aqui [señala el lugar que ocupa el semicírculo 2 en la pizarra (Imagen 9b)] ¿Entonces por dónde sería? [se refiere a la localización del eje de reflexión].

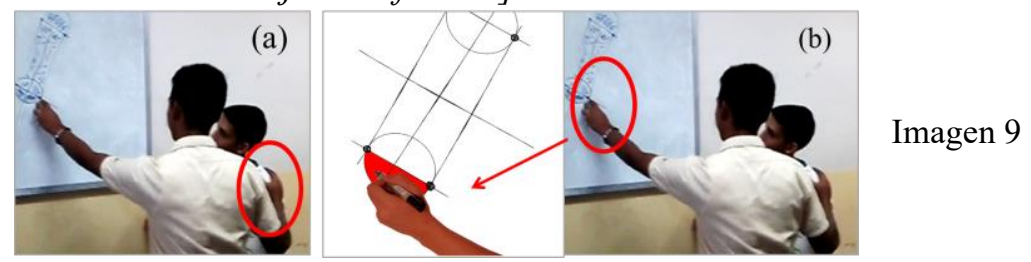

Más adelante, se encontraron evidencias del modo en que Yolanda ofreció su ayuda a Santiago ante la imposibilidad de identificar sobre la pizarra la mediatriz que sirvió de eje de reflexión en la técnica. Esta forma de cuidado del otro se interpreta como una actitud solidaria promovida por Juan al invitar a Yolanda a colaborar con Santiago, atendiendo con ello la necesidad del joven. A pesar de su disposición, el análisis muestra a una Yolanda más preocupada en expresar adecuadamente sus ideas que en ofrecer una verdadera ayuda a Santiago, lo que la lleva a dudar de si misma como se aprecia en el siguiente fragmento:

Juan: Levántate un momento [dirigiéndose a Yolanda], intenta darle a él [a Santiago] una explicación. Vamos a esperar qué nos dice ella [dirigiéndose al grupo].

Luis: Dale Yolanda.

Yolanda: Si tú vas a... [se dirige a Santiago mientras coloca el brazo en la posición del eje de reflexión (Imagen 10a)]. Aja, si ya... [funge el ceño en señal de duda y dirige su mirada a Juan (Imagen 10b)].
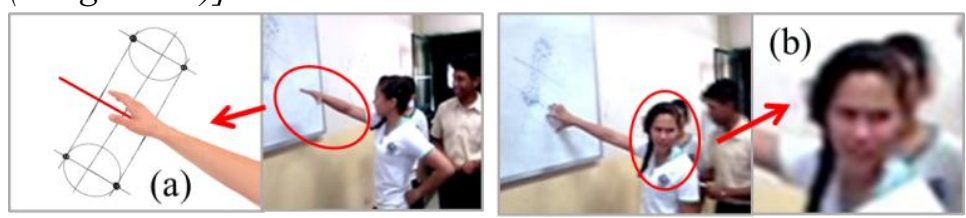

Imagen 10

En ese momento, Elías detecta la tensión en Yolanda y se muestra solidario, ofreciendo su ayuda en el preciso momento en que ella lo necesitaba. La ayuda de Elías consistió en sugerir a la joven un retorno a los pasos de construcción del semicírculo discutidos antes de dibujar la mediatriz. Esta sugerencia fue valorada por Juan, quien junto a Elías ajustan el dibujo en la pizarra según los pasos de la técnica realizados antes de obtener la mediatriz. Con este nuevo panorama, Yolanda realiza un nuevo acto de solidaridad con Santiago, produciendo una nueva 
explicación en la que se muestra más segura y concentrada en el joven, como se constata en el siguiente segmento:

Yolanda: Si tú [se refiere a Santiago] vas a reflejar esto [señala el semicírculo 1 con la mano extendida (Imagen 11a)], necesitas la recta que va aquí [realiza un movimiento de la mano en la dirección del eje de reflexión (Imagen 11b) ]... O sea, lo que ves es que ella [la recta] se abre asi hasta el final, o sea, que éste y éste se equiparen [se refiere a las distancias entre la recta de reflexión y cada centro de los semicírculos 1 y 2 (Imagen 11c)].

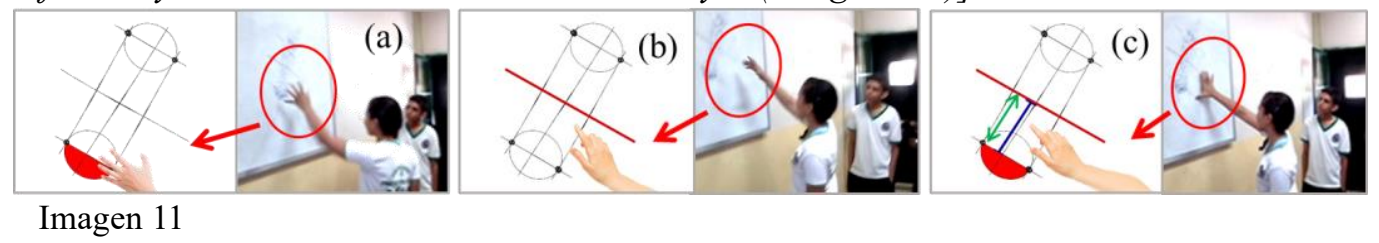

En cuanto a la responsabilidad, se hallaron evidencias del modo en que Juan (el promotor) trata de hacer que Leonardo y Elías se dispongan a cooperar con Santiago en su intento por identificar la mediatriz de un segmento a partir de un conjunto de rectas perpendiculares a este objeto, mostradas en un dibujo, realizado por Juan en la pizarra y localizado por encima del boceto previamente dibujado. A partir del diálogo que mantienen Juan y Santiago sobre este asunto, la postura corporal de Leonardo revela el interés del joven en participar de la discusión, señal que es captada inmediatamente por el promotor, quien redirige sus preguntas hacia este alumno, invitándole a obrar junto a Santiago en la búsqueda de una respuesta favorable para todos.

Juan: [Dibuja un segmento a y una recta perpendicular a ésta (Imagen 12)].



Juan: ¡Aja! ¿Qué es una recta perpendicular? [dirige la pregunta a Santiago]. Tengo ésta [señala con el dedo la recta perpendicular al segmento a (Imagen 13a)]. Ésta es perpendicular al segmento [segmento a]. Ésta [recta] también es perpendicular al segmento [dibuja una segunda recta perpendicular al segmento a, que la intersecta (Imagen 13b)], porque aqui hay un ángulo recto [marca ángulo recto que forma ésta línea con el segmento a]. Ésta que pasa por aqui también es perpendicular [dibuja una tercera recta perpendicular al segmento a, que la intersecta (Imagen 13c)], y esta recta que pasa por todo el extremo, también es perpendicular [dibuja una cuarta recta perpendicular al segmento a, por uno de sus extremos (Imagen 13d)]. $Y$ ésta también es perpendicular [dibuja una quinta recta perpendicular fuera del segmento (Imagen 13e)]. ¿Cuántas perpendiculares hay? ¡Uf!, muchísimas. ;Infinitas! Pero solo una es la mediatriz. Solo una. 

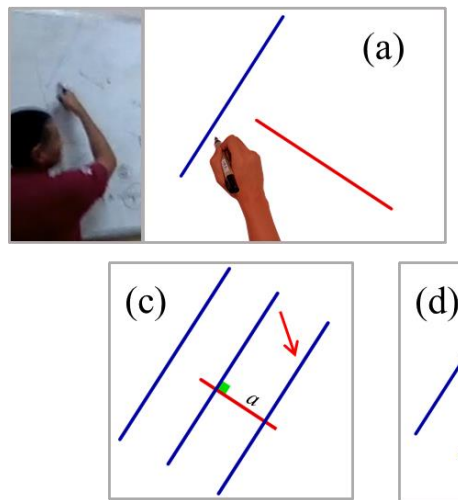
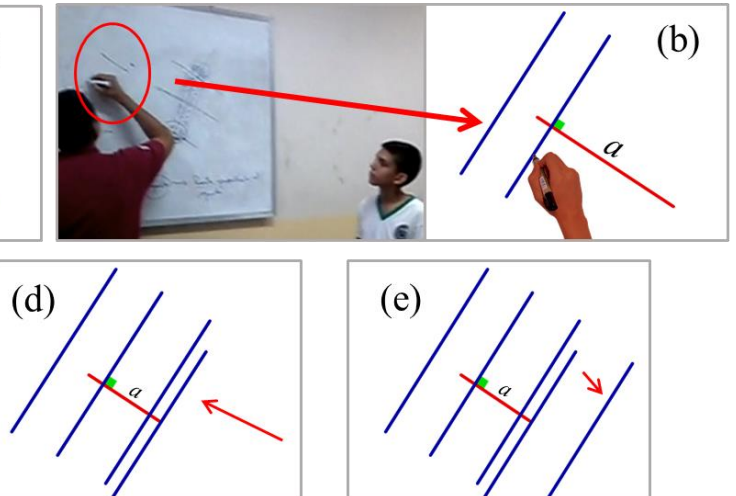

(e)

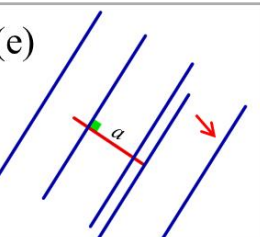

Imagen 13

Juan: ¿Cuál es? De todas las que son perpendiculares al segmento. ¿Ésta? [Pregunta a Santiago, señalando la recta de la Imagen 12]. No puede ser ésta tampoco [señala la recta dibujada en la Imagen 13a]. Ni ésta, ni ésta, ni ésta [señalando las restantes rectas dibujadas], con todo y que son perpendiculares al segmento. ¿Cuál es la recta [mediatriz de a]? [dirige la pregunta a Leonardo y le señala (Imagen 14)].

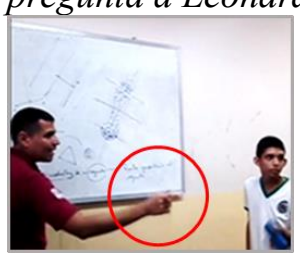

Imagen 14

La disposición a responder materializada en las acciones de Leonardo se produce desde el momento en que este joven utiliza su cuerpo para producir una respuesta que no puede dar mediante palabras, comprometiéndose, responsablemente, con la discusión que mantienen Juan y Santiago. En ese preciso momento, Elías interviene para dar la respuesta que Leonardo no puede ofrecer, pero la interrupción de este joven no rompe con la interacción entre Juan y Leonardo, avanzando hacia un punto en el cual este último intenta producir un discurso que satisfaga las necesidades del promotor y pueda servir para que Santiago comprenda la situación.

Juan: ¿Cuál es la recta? [dirige la pregunta a Leonardo y le señala (Imagen 14)].

Leonardo: La [recta] que pasa por ...

Juan: ¿La [recta] que pasa por donde?

Elías: Por el centro.

Leonardo: Por la... [junta sus manos frente a su cara para referise al segmento a (Imagen 15)].

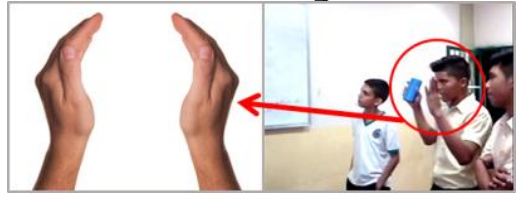

Imagen 15

Juan: ¿Por el centro? [en respuesta a Elías]. Los segmentos no tienen centro, lo que tiene centro es la circunferencia. Vamos [Leonardo], casi casi respondes. ¿La [recta] que pasa por dónde? Leonardo: Por la mitad de los extremos del segmento [junta sus manos para referise al segmento a (Imagen 16a), y luego coloca su mano derecha en posición recta para indicar el punto medio de a (Imagen 16b)].

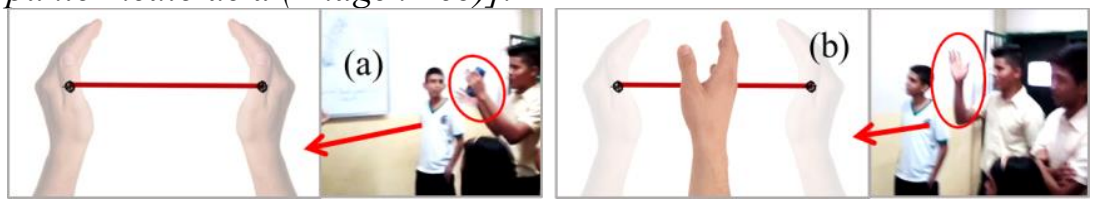

Imagen 16

Juan: ¿El segmento? Pero recuerda que el segmento no tiene centro. Lo que tiene centro es la circunferencia. 
Leonardo: Por eso digo, la mitad.

Juan: Pero, ¿la mitad? Si yo tengo el segmento [señala al segmento a], la mitad del segmento es este (Imagen 17a). Aqui está la mitad del segmento, y aqui está la otra mitad. ;Mira! [dibuja dos partes congruentes del segmento a (Imagen 17b)]. Si yo junto estas dos mitades, me da el segmento que tengo aquí.

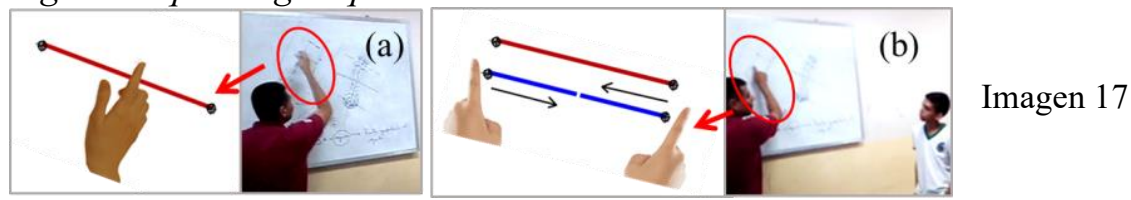

Juan: Pero yo no quiero la mitad del segmento. ¿Qué quiero yo? [dirige la pregunta a los presentes]. Para poder dibujar la recta, ¿qué necesito? ¿Qué necesito?

Leonardo: Un punto.

Juan: ¡Un punto! Entonces eso [se refiere al punto medio del segmento a] no se puede llamar "mitad" del segmento, sino ...

Leonardo: Punto de intersección.

Juan: Punto medio. Se debe llamar punto medio. ¿Punto medio de qué?... Del segmento [segmento a]... Entonces yo ubico el punto medio, Elías. Luego de ubicar el punto medio del segmento [hace una marca sobre el segmento a para indicar su punto medio (Imagen 18a)], y no se llama "centro", ni se llama "la mitad". Que [el punto] esté en la mitad del segmento, eso es otra cosa, pero se llama "punto medio". Y por ahí, ¿quién va a pasar? [dibuja la mediatriz del segmento a (Imagen 18b)] .

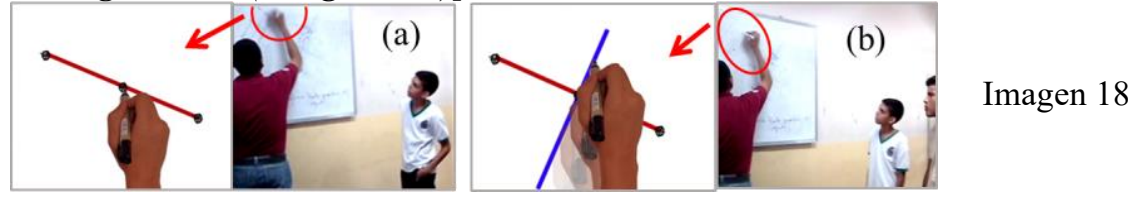

Elías: La recta.

Juan: La "bendita" mediatriz esa que yo quiero.

Cabe destacar que, en diversos momentos de la sesión, Elías tuvo la intención de ofrecer respuestas sin pensar en el prójimo, como lo muestra el fragmento anterior. Tal actitud preocupa a Juan y éste dialoga, respetuosamente, con el alumno a fin de hacerle ver que no siempre tendrá una respuesta para todo y que más vale escuchar lo que otros tienen que decir para cooperar que precipitarse en responder. Este modo de actuación revela la forma en que el promotor busca que Elías acepte la pluralidad de perspectivas que se producen al comunicar una técnica de construcción y aprenda un modo de conectarse con el prójimo.

A pesar de ello, en la siguiente interacción entre Juan y Elías se observa cómo el joven se resiste a aceptar la ayuda ofrecida por el promotor, evitando, así, una participación más responsable. Frente a tal resistencia, Juan decide no increpar al alumno, más opta por persuadirle haciéndole ver que, en ese preciso momento, el objetivo de la discusión era ayudar a Santiago. Es importante resaltar el modo en que el promotor le hace saber a Elías que está dispuesto a atender su necesidad, mediante el ofrecimiento de un espacio de tiempo posterior para que el alumno pueda explicar mejor su punto de vista, muy a pesar de que el promotor parece no estar de acuerdo con tal planteamiento.

Elías: Lo que pasa es que yo se lo digo para que usted [se dirije al promotor (Imagen 19)] entienda por qué yo hice... 


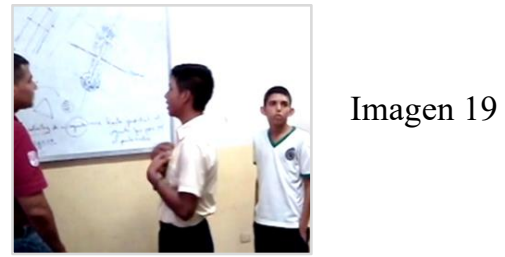

Juan: Bueno, cuando terminemos esta reflexión quiero que vayamos al GeoGebra para que me expliques cómo dibujar la mediatriz de un segmento a partir de dos rectas paralelas. Me lo vas a explicar [ señala a Elias (Imagen 20)], porque yo no te entiendo y yo te quiero entender. Vamos a terminar la reflexión.

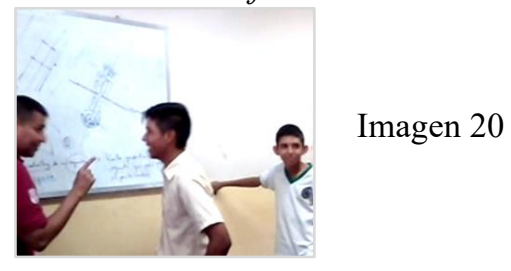

\section{Discusión y conclusiones}

En esta investigación nos hemos apoyado en una perspectiva histórico-cultural del aprendizaje matemático para dar cuenta de tres formas de colaboración humana (responsabilidad, compromiso y cuidado del otro), que se han puesto de manifiesto en la interacción de un grupo de profesores de matemática y alumnos de un club GeoGebra, involucrados en la comunicación de la técnica de construcción de un semicírculo con GeoGebra.

El análisis de los datos permitió detectar, por un lado, cuatro segmentos que dieron cuenta del tipo de colaboración reveladas en el análisis y cómo éstas fueron surgiendo en la actividad y, por otro, siete segmentos que muestran el modo en que los profesores promovieron en los alumnos tales formas de colaboración.

En lo que respecta a la responsabilidad, esta fue la forma de colaboración con más presencia en el trabajo de promotores y alumnos, debido quizás al esfuerzo de Juan (el promotor) por mantener una relación dialógica: (i) con Santiago, (ii) entre los alumnos y (iii) entre él y los demás alumnos. En correspondencia con León y Lasprilla (2018), el tipo de relación dialógica producida en la sesión fue el medio que contribuyó a una articulación entre las acciones de los individuos y la actitud responsable de asumir el compromiso de llegar a comprender la técnica de manera conjunta.

De estas formas de manifestación de la responsabilidad, queremos destacar que la segunda (entre los alumnos) fue la más difícil de mantener en el transcurso de la actividad, pues creemos que la experiencia escolar de Santiago, Elías, Yolanda y Leonardo ha sido permeada por años de formación individualista, en la cual se ha tratado de que estos alumnos asuman la 
responsabilidad plena de su aprendizaje y, muy pocas veces, se le ha enseñado a ver por el otro. Sin embargo, a través de su actuación responsable, Juan se esfuerza tanto por hacer conscientes a los alumnos de la situación problemática en la que se encuentra Santiago, como por fomentar en ellos la colaboración y la ayuda mutua. Esta manera de actuar del promotor propicia que los alumnos respondan al llamado del otro, lo que representa un elemento fundamental de la responsabilidad como forma de colaboración (RADFORD, 2017).

En cuanto al compromiso, esta forma de colaboración soló se manifestó por parte del promotor (de Juan) hacia los alumnos, lo que puede parecer natural dentro de las subjetividades de todo profesor comprometido con el aprendizaje de sus alumnos. Siguiendo a Radford (2017), este tipo de compromiso expresa esa promesa de hacer todo lo posible e imposible para fomentar el bien común en el desarrollo de la labor conjunta. Esto explicaría el esfuerzo reiterado de Juan por hacer que Elías, Yolanda y Leonardo proporcionen alguna ayuda a Santiago, indicio de la intención del profesor de promover el compromiso en estos alumnos.

En lo que respecta al cuidado del otro, encontramos evidencias de la manera cómo el promotor protege a Santiago de la imposición de ideas ajenas al joven (incluyendo las del promotor de su club) y también, como mencionamos anteriormente, de la forma como el mismo profesor promueve el cuidado del otro en los jóvenes al tratar de hacerlos sensibles ante los estados de frustración de Santiago, por ejemplo, cuando busca que Elías, Yolanda y Leonardo tengan alguna reacción responsable al llamado de auxilio de Santiago, expresado en sus gestos y acciones.

Para finalizar, queremos hacer mención de tres aspectos que incidieron en la manifestación y promoción de estas formas de colaboración a lo largo de la sesión.

\subsection{El modo de gestionar la comunicación de la técnica}

Dada la naturaleza de la actividad, la comunicación de la técnica fue el medio por excelencia que convocó a promotores y alumnos a trabajar conjuntamente en la busqueda de la comprensión los pasos y acciones que componen la técnica, reduciendo al mínimo la participación individualista. Esto pudo deberse, en gran medida, a las capacidades del promotor para gestionar, de modo eficiente y responsable la comunicación de la técnica entre todos los involucrados, capacidades que constituyen parte del saber docente propio de los clubes GeoGebra y que fue reportado por Prieto y Ortiz (2019) en una investigación previa. En otras palabras, la relación dialógica revelada en el análisis fue dirigida al logro del objeto de la ESG y no al fomento del egoísmo y la competencia que imperan en las clases tradicionales. 


\subsection{La cultura individualista en la escuela}

El análisis arrojó información que revela cómo la cultura individualista aún sigue arraigada en las conductas de nuestros alumnos. Como lo sugieren los datos, algunas veces los jovenes mantuvieron una disposición a participar centrada más en los intereses propios y menos en las necesidades de todos, manifestando poca sensibilidad y una falta de capacidad para reconocer los signos de frustración en el prójimo.

Esta realidad fue enfrentada por el profesor a través de la promoción de formas de colaboración como la responsabilidad y el cuidado del otro, de modo tal que los alumnos fueran capaces de reconocer las necesidades y pedidos de ayuda de Santiago y, en consecuencia, actuaran de manera responsable. Este tipo de acciones del promotor contribuyen a fracturar la relación profesor-alumnos que domina en muchos de nuestros centros escolares, y que mantiene distanciados a estos sujetos en aras de un aprendizaje genuino (RADFORD, 2017).

\subsection{La resistencia al cambio}

Un hecho importante de destacar fue la resistencia al cambio, expresada en uno de los alumnos, es decir, la negativa de Elías a reconocer las perspectivas de sus compañeros (pluralidad de perspectiva), tratando de imponer en cada momento su punto de vista como el único válido en el grupo, sin tomar en cuenta la opinión de los demás. Para mediar con esta situación, el profesor se interesa por conocer las ideas de los alumnos, escuchar sus opiniones respetando los puntos de vista, sin dejar de atender las necesidades que emergen en la comunicación de la técnica. En el caso puntual del promotor, como sugiere Radford (2017), las acciones del profesor van dirigidas a crear condiciones iniciales para que los estudiantes asuman y adopten actitudes de respeto dentro y fuera de la actividad.

Aunque los resultados de esta investigación representan un avance en la comprensión de las relaciones sociales de producción que emergen en actividades de elaboración de simuladores con GeoGebra, el hecho de analizar una experiencia particular de simulación no garantiza la comprensión amplia de la ética detrás de las experiencias de elaboración de simuladores con GeoGebra. Concretamente, no se encontraron evidencias de la promoción de ciertas formas de colaboración, como es el caso del compromiso, lo que nos obliga a realizar nuevos estudios que ayuden a comprender por qué este tipo de cosas ocurre y cómo poder propiciar experiencias de elaboración más completas. Esta clase de estudios permitirán crear mejores condiciones para promover en los clubes una nueva ética comunitaria alrededor de la 
elaboración de simuladores, impactando inclusive en la formación de nuevos promotores de los clubes GeoGebra.

\section{Referencias}

ARZARELLO, F.; OLIVERO, F.; PAOLA, D.; ROBUTTI, O. A cognitive analysis of dragging practices in Cabri environments. ZDM, Berlin, v. 34, n. 3, p. 66-72, 2002.

BARTOLINI-BUSSI, M. Social interaction and mathematical knowledge. En: FURINGHETTI, F. (Ed.). Proceedings of the fifteenth annual conference of the international group for the psychology of mathematics education. Vol. 1. Assisi: PEM, 1991. p. 1-16.

BOERO, P.; DAPUETO, C.; FERRARI, P.; FERRERO, E.; GARUTI, R.; LEMUT, E.; PARENTI, L.; SCALIET, E. Aspects of the mathematics-culture relationship in mathematics teaching and learning in compulsory school. En: Proceedings of the 19th conference of the international group for the psychology of mathematics education. PME, 1995. Disponible en:

http://macosa.dima.unige.it/pub/pme/pme.htm.

BOGDAN, R.; BIKLEN, S. K. Investigação qualitativa em educação: uma introdução à teoria e aos métodos. Portugal: Porto, 1994.

DÍAZ-URDANETA, S.; PRIETO, J. L. Visualización en la simulación con GeoGebra. Una experiencia de reorganización del conocimiento matemático. En: SERRES, Y.; MARTÍNEZ, A.; INOJOSA, M.; GÓMEZ, N. (Ed.). Memorias del IX Congreso Venezolano de Educación Matemática. Barquisimeto: Asovemat, 2016. p. 445-453.

GUTIÉRREZ, R. E.; PRIETO, J. L.; ORTIZ, J. Matematización y trabajo matemático en la elaboración de simuladores con GeoGebra. Educacion Matematica, Mexico, v. 29, n. 2, p. 37-68, 2017.

LABORDE, C. Cabri Geómetra o una nueva relación con la geometría. En: PUIG, L. (Ed.). Investigar y enseñar: Variedades de la educación matemática. Madrid: Una empresa docente, 1997, p. 33-48.

LEÓN, O. L.; LASPRILLA, A. Enfoques necesarios para la reflexión sobre una ética comunitaria en la educación matemática. PNA, Granda, v. 12, n. 2, p. 81-95, 2018.

LEONTYEV, A.N. Activity and Consciousness: Philosophy in the USSR, problems in Dialectical Materialism. Moscow: Progress Publishers, 1977.

LERMAN, S. The function of language in radical constructivism: A Vygotskian perspective. En: GEESLIN, W.; GRAHAM, K. (Ed..). Proceedings of 16th conference of international group for the psychology of mathematics education. Vol. 2. New Hampshire: PME, 1992, p. 40-47.

MORENO-ARMELLA, L.; WALDEGG, G. Constructivismo y educación matemática. Educación Matemática, Mexico, v. 4, n. 2, p. 7-15, 1992.

MUÑOZ-CATALÁN, M.C.; CARRILLO, J.; CLIMENT, N. Modelo de análisis de interacciones en un contexto colaborativo de desarrollo profesional. En: MORENO, M. M.; ESTRADA, A.; CARRILLO, J.; SIERRA, T. A. (Ed.). Investigación en Educación Matemática XIV. Lleida: SEIEM, 2010. p. 451-462.

PARNAFES, O. What Does "Fast" Mean? Understanding the Physical World Through Computational Representations. The Journal of the Learning Sciences, Inglaterra, v. 16, n. 3, p. 415-450, 2007. 
PELEY, S. La rotación em la simuación de um brazo robótico. En: PRIETO, J. L.; GUTIÉRREZ, R.E (Comp.). Memorias del II Encuentro de Clubes GeoGebra del Estado Zulia. Venezuela: A. C. Aprender en Red, 2016. p. 249-257.

POWELL, A.B.; FRANCISCO, J.M.; MAHER, C.A. An Analytical Model for Studying the Development of Learners' Mathematical Ideas and Reasoning Using Videotape Data. Journal of Mathematical Behavior, v. 22, n. 1, p. 405-435, 2003.

PRIETO, J. L. Proyectos de simulación con GeoGebra: una estrategia del desarrollo del pensamiento científico desde el servicio comunitario. Trabajo de ascenso - Facultad de Humanidades y Educación, Universidad del Zulia, Maracaibo, 2017.

PRIETO, J. L.; GUTIÉRREZ, R. E. (Comp.). Memorias del I Encuentro de Clubes GeoGebra del Estado Zulia. Maracaibo: Aprender en Red, 2015.

PRIETO, J. L.; GUTIÉRREZ, R. E. (Comp.). Memorias del II Encuentro de Clubes GeoGebra del Estado Zulia. Maracaibo: Aprender en Red, 2016

PRIETO, J. L.; GUTIÉRREZ, R. E. (Comp.). Memorias del III Encuentro de Clubes GeoGebra del Estado Zulia. Maracaibo: Aprender en Red, 2017

PRIETO, J. L.; ORTIZ, J. Saberes necesarios para la gestión del trabajo matemático en la elaboración de simuladores con GeoGebra. Bolema, Rio Claro, v. 33, n. 65, p. 1276-1304, 2019.

RADFORD, L. La generalizzazione matematica come processo semiotico. La matematica e la sua didattica, v. 19, n. 2, p. 191-213, 2005.

RADFORD, L. Elementos de una teoría cultural de la objetivación. Relime, n. especial sobre Semiótica, Cultura y Pensamiento Matemático, p. 103-129, 2006.

RADFORD, L. The ethics of being and knowing: Towards a cultural theory of learning. En: RADFORD, L.; SCHUBRING, G.; SEEGER, F. (Ed.). Semiotics in mathematics education: Epistemology, history, classroom, and culture. Rotterdam: Sense Publishers, 2008. p. 215-234.

RADFORD, L. Sumisión, alienación y (un poco de) esperanza: hacia una visión cultural, histórica, ética y política de la enseñanza de las matemáticas. En: RAMIREZ, A.; MORALES, Y. (Ed.). Memorias del I Congreso de Educación Matemática de América Central y El Caribe. Santo Domingo: REDUMATE, 2013. p. 01-16.

RADFORD, L. De la teoría de la objetivación [On the theory of objectification]. Revista Latinoamericana de Etnomatemática, v. 7, n. 2, p. 132-150, 2014.

RADFORD, L. Methodological aspects of the theory of objectification. Revista Perspectivas da Educação Matemática, São Paulo, v. 8, n. 18, p. 547-567, 2015.

RADFORD, L. Ser, subjetividad y alienación. En: D’AMORE, B.; RADFORD, L. (Ed.). Enseñanza y aprendizaje de las matemáticas: problemas semióticos, epistemológicos y culturales. Bogotá: Universidad Distrital Francisco José de Caldas, 2017. p. 139-165.

RADFORD, L. Pautas para repensar el sujeto y el objeto desde una epistemología de la solidaridad, en tiempos de una educación para el mercado y el consumo. En: ÁVILA, A. (Coord.). Rutas de la Educación Matemática. México D.F.: SOMIDEM, 2018. p. 89-105.

RUBIO, L.; PRIETO, J. L.; ORTIZ, J. La matemática en la simulación con GeoGebra. Una experiencia con el movimiento en caída libre. International Journal of Educational Research and 
Innovation, v. 2, p. 90-111, 2016.

SÁNCHEZ, I. C.; PRIETO, J. L. Algunos ejemplos del uso experimental del GeoGebra en situaciones de simulación y diagramación. En: SERRES, Y.; MARTÍNEZ, A.; INOJOSA, M.; GÓMEZ, N. (Ed.). Memorias del IX Congreso Venezolano de Educación Matemática. Barquisimeto: Asovemat, 2016. p. $466-478$.

SÁNCHEZ, I. V.; PRIETO, J. L. Características de las prácticas matemáticas en la elaboración de simuladores con GeoGebra. Números. Revista de Didácticas de las Matemáticas, v. 96, p. 97-101, 2017. 